\title{
UCAV PW-124 - A DESIGN EFFORT UNDERTAKEN AT WARSAW UNIVERSITY OF TECHNOLOGY
}

\section{Z. Goraj}

Warsaw University of Technology, Warsaw, Poland.E-mail:goraj@meil.pw.edu.pl

Received 1104 2005, accepted 05122005

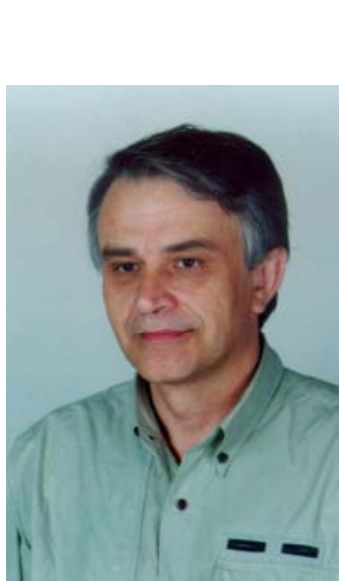

Zdobyslaw GORAJ, Prof

Education: MSc (Eng.) - 1972, PhD - 1977, D Sc - 1992, Prof - 2002.

Affiliations and functions: 1973 - 2002 - Warsaw University of Technology, Lecturer of Flight Dynamics; 1982 1989 - Light Aircraft Company PZL - Okecie - Senior Airplane Designer; 1992 - 1999 - Institute of Aviation Head of Flight Dynamics Group; 1993 - 1996 - Institute of Aeronautics and Applied Mechanics - Deputy Director; 1996-2002 - Vice Dean for Scientific Affairs at the Faculty of Power and Aeronautical Engineering. Experience: Aircraft Designer since 1982; Flight Dynamics Researcher since 1977; Main Organizer of the International Seminars entitled: „Recent Research And Design Progress In Aeronautical Engineering And Its Influence On Education” (1994-2000); Member of Editorial Boards of the following Journals: (1) Aircraft Design (Holland) (2) Journal of Aerospace Engineering (United Kingdom) (3) Turbo And Jet-Engines (Israel) (4) Transactions of the Institute of Aviation - Scientific Quarterly (Poland); Polish Coordinator And Representative in European Fifth Framework Program devoted to Unmanned Aerial Vehicles - Coordinator of UAVNET And CAPECON projects;

Lectures in Foreign Institutions: 1997 - Kyushu University, Japan, Long Endurance High Altitude Unmanned Aerial Vehicles; 1998 - Bristol University - UK, Panel methods in teaching of airplane design; 1999 - Saint-Cyr France, Panel methods - theory and practice; Old Dominion University, Virginia, USA; Coupled Flight Dynamic / Panel Method Tool for Conceptual Design And Analysis of Existing Vehicles; 2000 - Boeing - Saint Louis, USA, Coupled Flight Dynamic / Panel Method Analysis; Israel Aircraft Industry, Design and Flight Dynamics of a HALE UAV; 2001 - London, Kingston University, Civil Unmanned Aerial Vehicles (UAVs) "State of the Art And Challenges for the Future.

Teaching: Mechanics of Rigid Bodies, Flight Mechanics, Flight Dynamics, Airplane Aerodynamics and Airplane Design.

Publications: Author of numerous journal and conference papers (more than 80).

Present position: Head of Department of Airplane And Helicopter Design; Course Director for Aerospace Engineering Program in WUT.

\begin{abstract}
This paper presents a conceptual design project developed at the Warsaw University of Technology and focused on an unmanned aerial vehicle being able to fly at low and medium altitude, with a special emphasis put on selecting the platform best suited for the planned mission. Design and research activity necessary to complete the project successfully is based on the international experience gained by the university team within a number of the past very successful projects, mainly projects supported by European Union within the $\mathrm{V}$ and VI scientific frameworks. The project deals with a highly maneuverable unmanned aerial vehicle of low gust sensitivity and reduced radar, infrared, and acoustic signature. Aircraft mission, power unit, aerodynamics and many design details are shown and discussed.
\end{abstract}

Keywords: aircraft design, unmanned aerial vehicles, high manoeuvrability.

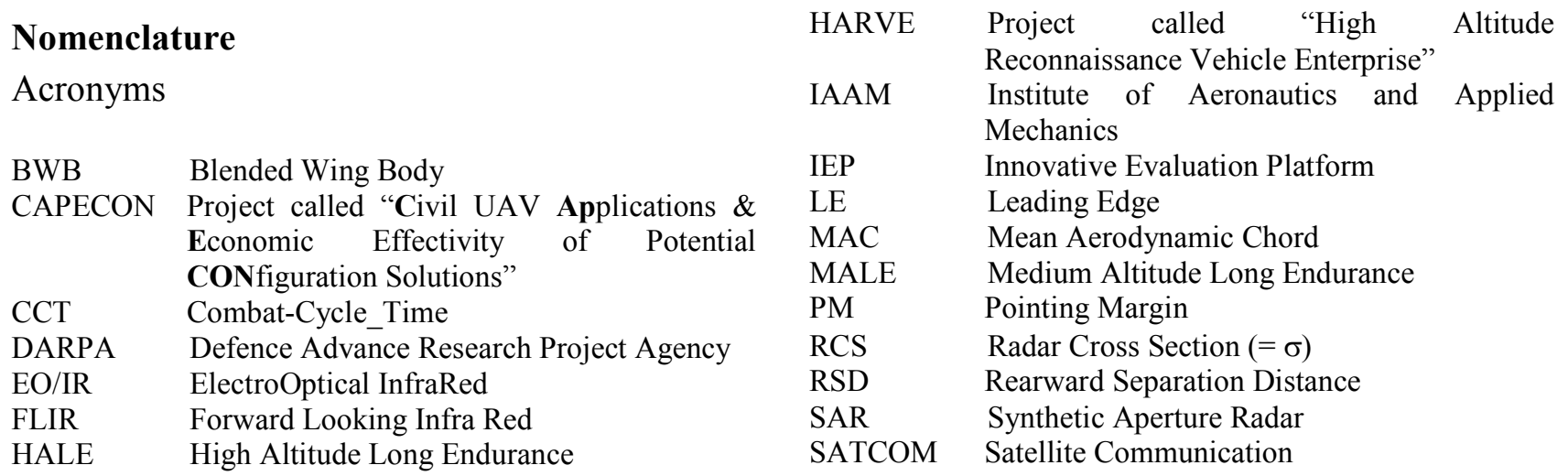




\begin{tabular}{|c|c|}
\hline UAV & Unmanned Aerial Vehicle \\
\hline UAVNET & Unmanned Aerial Vehicle Network \\
\hline VSAERO & Panel Code, AMI Inc. \\
\hline WUT & Warsaw University of Technology \\
\hline \multicolumn{2}{|l|}{ Symbols } \\
\hline$c_{D}$ & $=$ drag coefficient \\
\hline $\mathrm{c}_{\mathrm{Di}}$ & $=$ induced drag coefficient \\
\hline $\mathrm{C}_{\mathrm{L}}$ & $=$ lift coefficient \\
\hline $\mathrm{C}_{\mathrm{L}, \mathrm{MAX}}$ & $=$ maximum lift coefficient \\
\hline $\mathrm{C}_{\mathrm{L} \alpha}$ & $=$ lift-curve slope \\
\hline G & $=$ shear modulus \\
\hline $\mathrm{m}$ & $=$ aircraft weight \\
\hline $\mathrm{Ma}$ & $=$ Mach number \\
\hline q & $=$ dynamic pressure \\
\hline $\mathrm{P}_{\mathrm{s}}$ & $=$ specific excess power \\
\hline $\mathrm{Re}$ & $=$ Reynolds number \\
\hline S & $=$ wing gross area \\
\hline $\mathrm{S}_{\mathrm{i}}$ & $=$ reference area \\
\hline W & $\begin{aligned}= & \text { vertical displacement of UAV, positive if } \\
& \text { upwards }\end{aligned}$ \\
\hline $\mathrm{W}_{\mathrm{g}}$ & $=$ vertical gust (positive if upwards) \\
\hline$\alpha$ & $=$ angle of attack \\
\hline$\beta$ & $=$ angle of sideslip \\
\hline$\delta_{\mathrm{F}}$ & $\begin{array}{l}=\text { tab-flap deflection (positive if TE goes } \\
\text { down) }\end{array}$ \\
\hline$\delta_{\mathrm{E}}$ & $\begin{aligned}= & \text { elevon deflection (positive if } \mathrm{TE} \text { goes } \\
& \text { down) }\end{aligned}$ \\
\hline$\delta_{\mathrm{El}}, \delta_{\mathrm{Er}}$ & 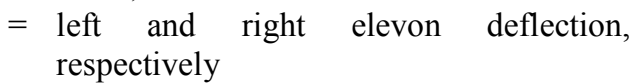 \\
\hline$\sigma$ & $=$ radar cross section $(\mathrm{RCS})$ \\
\hline$\rho$ & $=$ air density \\
\hline $\mathrm{t}$ & $=$ time \\
\hline
\end{tabular}

\section{Introduction}

Design and research efforts devoted to UAVs started in the Institute of Aeronautics and Applied Mechanics at the beginning of the nineties $[35,5,4,12,23,10]$. One of the first projects in this area, focused on a HALE surveillance UAV, was HARVE [35]. It was submitted for consideration to DARPA in 1995 and then published in 1999 (Ref. 24). The international projects called UAVNET $[33,9,30,36,1,28,27,21]$ and CAPECON $[2,20,15,22$, $18,14]$, supported by the European Union within the V Framework have had an important influence on the UAV activity in IAAM. The CAPECON project, launched in May 2002, is devoted to developing new configurations of MALE, HALE, and Rotary and accentuates some universal aspects and features of all aerospace designs, namely design, new materials, aeroelastic phenomenon, safety, reliability, cost, and economical competitiveness. A special emphasis was put on selecting the platform best suited for the planned mission. The trade-off between aerodynamic efficiency, performance, flight stability, selection the flight control system, payload and sensor's volume, reliability and safety was reviewed. Within the CAPECON project, the IAAM was responsible both for MALE [16], powered by single piston engine (called as PW-103), and HALE [15] powered by two turbofan engines (called as PW-114). Experience gained within the CAPECON project was important in planning and realizing the successive projects (see also Ref. 23-30). In this paper, a highly maneuverable unmanned aerial vehicle of low gust sensitivity and reduced radar, infrared, and acoustic signature, called PW-124, will be presented. High maneuverability and reduced signature are of great importance in military application [34]. Universities do not have both the experience and financial resources to carry out such research from scratch to a successful end. However, universities traditionally create bright ideas, have highly motivated young researchers, and in our opinion can run such project up to a certain line. The university effort can include the whole conceptual and preliminary project and even in-flight tests using a scaled model. Warsaw University of Technology successfully tested a few scaled flying models and now is a partner in the big Integrated Projected of European Union called NACRE (VI FR Integrated Project: "New Aircraft Concept Research"), launched in 2004 and focused on novel Airbus configurations. One of the tasks in this project will be devoted to in-flight tests of IEP (Innovative Evaluation Platform) PW-124 will be widely presented in next chapters. In this paper, an emphasis is put on aircraft dynamics [11], especially maneuverability and agility [29, 24]. Some preliminary results obtained by the WUT team were published earlier during a AIAA conference in Chicago [13] and the UCAV conference held in London in 2004 [17]., This design effort is however not finished yet and further studies, especially those devoted to the influence of design layout on agility assessment are needed.

\section{PW-124 - a high maneuverability, low radar signature UAV design project}

The main goals of the program called PW-124 are to design, build, and prepare the flight tests of a small, highly manoeuvrable unmanned aerial vehicle with reduced radar, infrared, and acoustic signature. Important features of the program and the platform are as follows:

- $\quad$ High manoeuvrability - load factor of order 15

- Low cost due to light weight and small dimensions (using admittedly very uncertain estimates of flyaway cost, the cost per empty weight seems remarkably similar to modern fighter aircraft. For example, the figure for the F-22 is approximately $\$ 6000 / \mathrm{kg}$, so for empty weight equal to $500 \mathrm{~kg}$, one can obtain \$3 mln per aircraft. Because PW124 does not need such a sophisticated software and on-board computer to fight simultaneously with a big number of enemy aircraft, so its cost will be essentially lower, probably around $\$ 1 \mathrm{mln}$ per aircraft) 
- $\quad$ Cheap turbojet engine (Microturbo TRI 60-5; SLS $440 \mathrm{kG}$ Thrust)

- $\quad$ Essential Ph.D. student participation in the design effort

- $\quad$ On-board equipment, engine, selected sensors, and avionics will be acquired from industrial cooperators interested in e future production

- $\quad$ Highly sophisticated carbon fibre structure, light and of quite strength

- Compact conFig. uration based on cranked delta wing, endowed with fixed slots, tab-flaps, and elevons / rudderons

- $\quad$ SAR, FLIR, and "flat" SATCOM (if ordered)

- Radius of mission equal to $200 \mathrm{~km}$

- Internal container to carry payload hidden in the body (volume not less than $2 \mathrm{~m} \times 0.6 \mathrm{~m} \mathrm{x} 0.5$ $\mathrm{m})$

- Low sensitivity to gust will be achieved due to relatively low lift-curve slope of order 2.2 per radian and a moderate wing loading of order 60 $\mathrm{kg} / \mathrm{m}^{2}$.

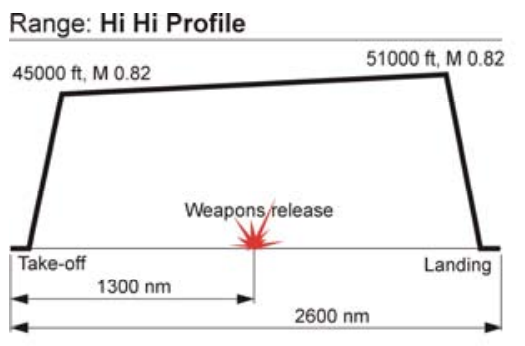

Range: Hi Lo Hi Profile $45000 \mathrm{ft}, \mathrm{M} 0.8250000 \mathrm{ft}, \mathrm{M} 0.82$

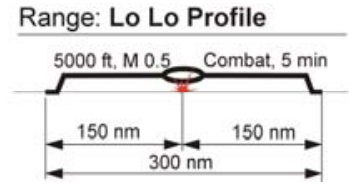

Fig 1. Typical UCAV missions - scenario of offensive flight

UCAVs can be used in many combat missions. A typical mission is the weapon release, which can be realized from either from high (the so-called Hi_Hi_profile) or low (the so-called Hi_Low_Hi_profile) altitude. The PW-124 aircraf, because of its limited weight and range, can perform the so-called Lo_Lo_mission, Fig. 1. Such a mission is shown at Fig. 2. Aircraft ascends to $1500 \mathrm{~m}$, flies approximately $200 \mathrm{~km}$ with the speed corresponding to the best specific range, then descends to $200 \mathrm{~m}$, manoeuvres during a 5- min time period at full thrust, then ascends again to $1500 \mathrm{~m}$ and returns back to base. Of course, the horizontal flight altitude and the height of manoeuvring depend on local conditions and can be slightly changed with respect to the mission of Fig. 2, if necessary.

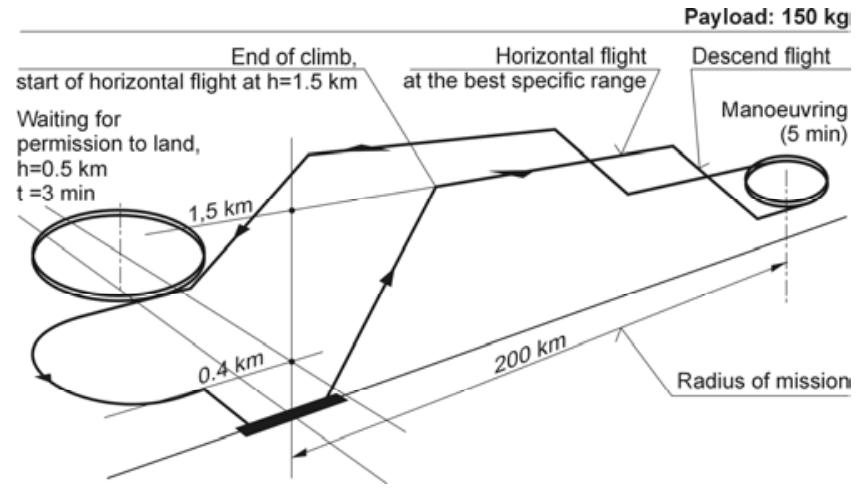

Fig 2. Typical mission of PW-124

Current fighter aircraft can not exceed load factors greater than eight, first of all because of the physiological limits of pilots. Analysts expect that in future combats at least selected high-g maneuvers can be performed by unmanned aerial vehicles. Among examples, there is an escape from adversary missile or many-on-many air battle scenario when a friendly UCAV will try to outmaneuver adversary aircraft and launch its weapon first. A number of papers devoted to the assessment of aircraft agility have been published, for example see [29, 24]. Very comprehensive agility concept and measures were defined by B. Tamrat [29]. These agility measures include the socalled "pointing margin" (PM), see Fig. 3, relative energy state $\left(\mathrm{V} / \mathrm{V}_{\mathrm{C}}\right)$, combat cycle time (CCT), see Fig. 4 for characterising pitch agility, and the rearward separation distance (RSD) for characterising roll agility. In this paper, the pointing margin (PM) and combat cycle time (CCT) were taken into account for selecting wing loading.

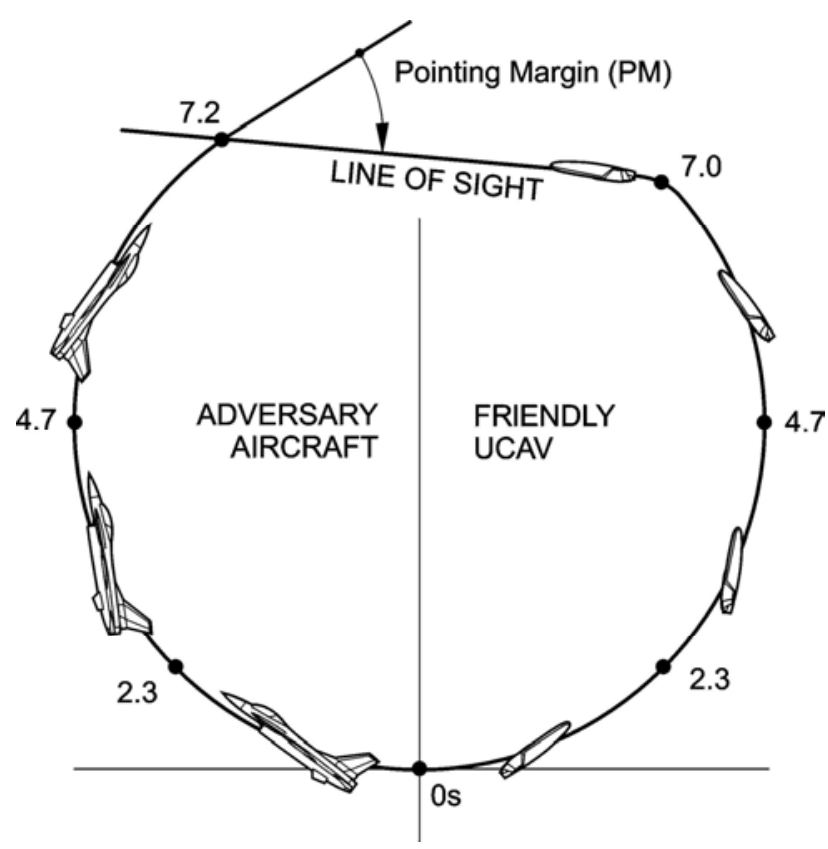

Fig 3. Pointing Margin (PM) is used to assess combat agility, see also [29] 


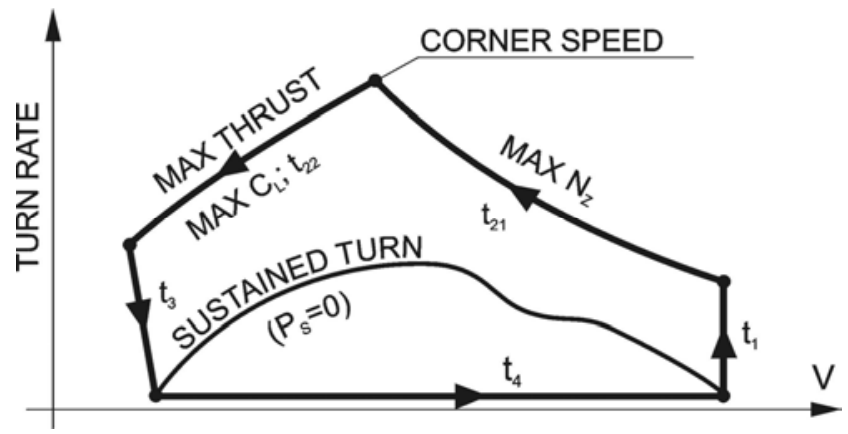

Fig 4. Combat Cycle Time $\left(t_{1}+t_{21}+t_{22}+t_{3}+t_{4}\right)$ is used to measure combat agility, from [29]

\section{A. Aircraft layout and short description}

PW-124 is designed as a blended wing body configuration, made of metal and composite materials, Fig. 5-7. Wing control surfaces provide longitudinal balance. Relatively high wing dihedral $\left(19.6^{\circ}\right.$ on inner wing-body segment and $31^{\circ}$ on outer wing, Fig. 5) provide directional stability. The airplane is equipped with retractable landing

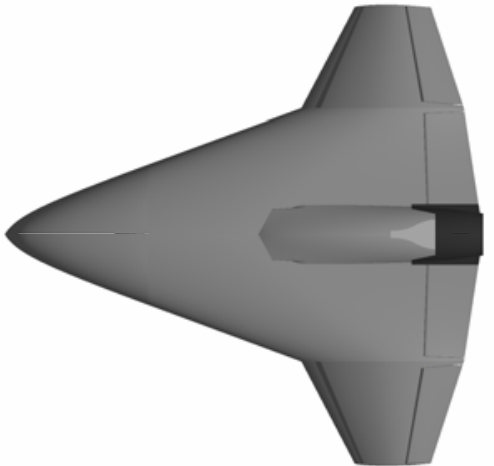

Fig. 6. PW-124 - top view gear with controlled front leg that allows operation from conventional airfields.

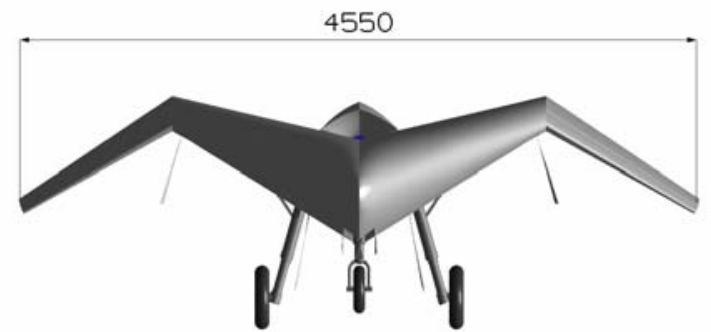

Fig 5. PW-124 - front view (span in [mm])

The power unit consists of one turbo-jet engine designed by the French company MicroTurbo. The unit, the model TRI $60-5$, has 360 daN thrust at SL and zero speed and SFC of order $1.4 \mathrm{~kg} /\left(\mathrm{daN}^{*} \mathrm{~h}\right)$ depending on altitude and Mach number, Fig. 8. Maximum longitudinal load factor is equal to 15 , normal load factor is 8 but can be increased at the request of a client.

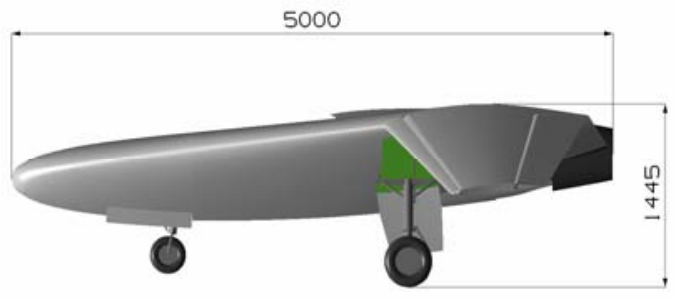

Fig. 7. PW-124 - side view (length and height in [mm])

Table 1. Technical data

\begin{tabular}{|l|c|}
\hline Wing span & $4.5 \mathrm{~m}$ \\
\hline Wing area & $11.8 \mathrm{~m}^{2}$ \\
\hline Body length & $5 \mathrm{~m}$ \\
\hline Height (in flight) & $0.9 \mathrm{~m}$ \\
\hline Height (on runway) & $1.55 \mathrm{~m}$ \\
\hline Aspect ratio & 1,76 \\
\hline Payload volume (length x width x height) & $2 \mathrm{~m} \times 0.6 \mathrm{~m} \mathrm{x} 0.5 \mathrm{~m}$ \\
\hline Empty weight & $300 \mathrm{~kg}$ \\
\hline Payload & $200 \mathrm{~kg}$ \\
\hline Fuel weight & $400 \mathrm{~kg}$ \\
\hline Nominal take-off weight & $800 \mathrm{~kg}$ \\
\hline Maximum take-off weight & $900 \mathrm{~kg}$ \\
\hline Maximum manoeuvring weight & $650 \mathrm{~kg}$ \\
\hline Take-off thrust & $4.4 \mathrm{kN}$ \\
\hline Maximum wing loading & $78 \mathrm{~kg} / \mathrm{m}^{2}$ \\
\hline Manoeuvring wing loading & $56.5 \mathrm{~kg} / \mathrm{m}^{2}$ \\
\hline Manoeuvring thrust loading & $148 \mathrm{~kg} / \mathrm{kN}$ \\
\hline Maximum thrust loading & $204 \mathrm{~kg} / \mathrm{kN}$ \\
\hline Payload loading & $17.4 \mathrm{~kg} / \mathrm{m}^{2}$ \\
\hline Payload/take-off thrust & $45.5 \mathrm{~kg} / \mathrm{kN}$ \\
\hline
\end{tabular}


Table 2. PW-124 main geometric data

\begin{tabular}{|c|c|c|}
\hline Reference wing area & 11.5 & $\mathrm{~m}^{2}$ \\
\hline Span & 4.5 & $\mathrm{~m}$ \\
\hline Aspect ratio & 1.76 & \\
\hline MAC (Mean Aerodynamic Chord) & 2.75 & $\mathrm{~m}$ \\
\hline Outer wing taper ratio & 0.41 & \\
\hline Wing average thickness $\mathrm{t} / \mathrm{c}$ & 0.12 & $\%$ \\
\hline Fuselage length & 5 & $\mathrm{~m}$ \\
\hline \multicolumn{3}{|l|}{ Wetted area breakdown: } \\
\hline Outer wing & 2.6 & $\mathrm{~m}^{2}$ \\
\hline Body & 28.3 & $\mathrm{~m}^{2}$ \\
\hline Total & 30.9 & $\mathrm{~m}^{2}$ \\
\hline
\end{tabular}

Body centre airfoil (with modified LE and TE) Body - outer wing junction airfoil (in the plane parallel to the vertical plane of aircraft symmetry) Outer wing airfoil (in the plane parallel to the vertical plane of aircraft symmetry)

NACA $0012-64$
NACA $65_{1}-412$
NACA $65_{1}-412$

\section{B. Aerodynamic analysis}

During the design process, the aircraft went through changes. Aerodynamic calculations were made using the VSAERO program. The program uses the potential compressible flow model (subsonic) combined with boundary layer.

Computation was solved for cruise flight condition:

- $\quad$ Mach number $\mathrm{Ma}=0.5$;

- $\quad$ Reynolds number Re=28E6

- $\quad$ Altitude flight (service ceiling) $\mathrm{H}=1500[\mathrm{~m}]$;

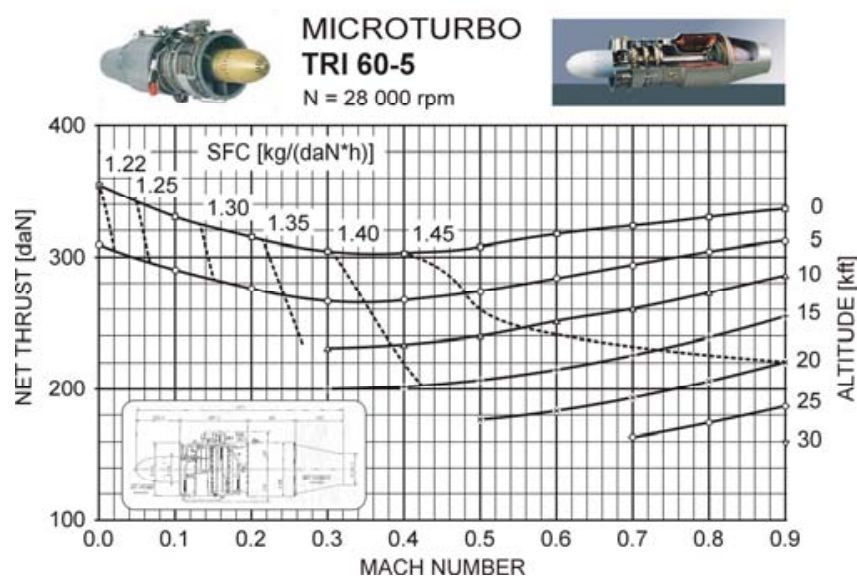

Fig 8. TRI 60-5 TurboJet engine was selected due to its high longitudinal load factor

\section{Wing}

Wing sections were selected to obtain the most desirable pressure distribution along the wing span. The natural decrease in pressure inside the delta wing area is compensated due to the relatively high incidence of the NACA 0012-64 airfoil used in the middle of the central (wing-body) part of the aircraft. The outer wings are twisted relative to their zero-lift line of the root sections (wing noses of the outer wing part are rotated downwards) to decrease pressure over the wing tips and to ensure that separation will start over the central part of the aircraft. This will guarantee good lateral control using elevons.

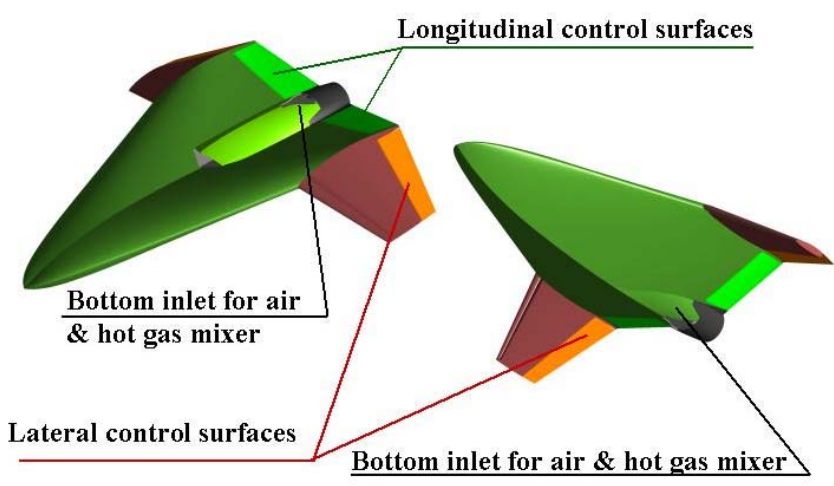

Fig 9. PW-124 - external layout. Control surfaces and air inlet are shown

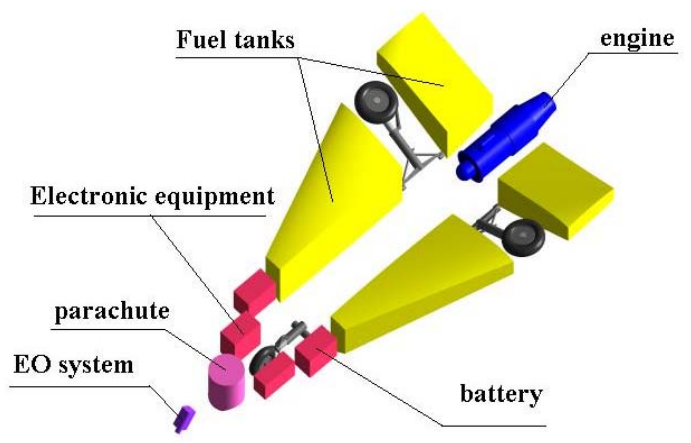

Fig 10. PW-124 - main systems layout

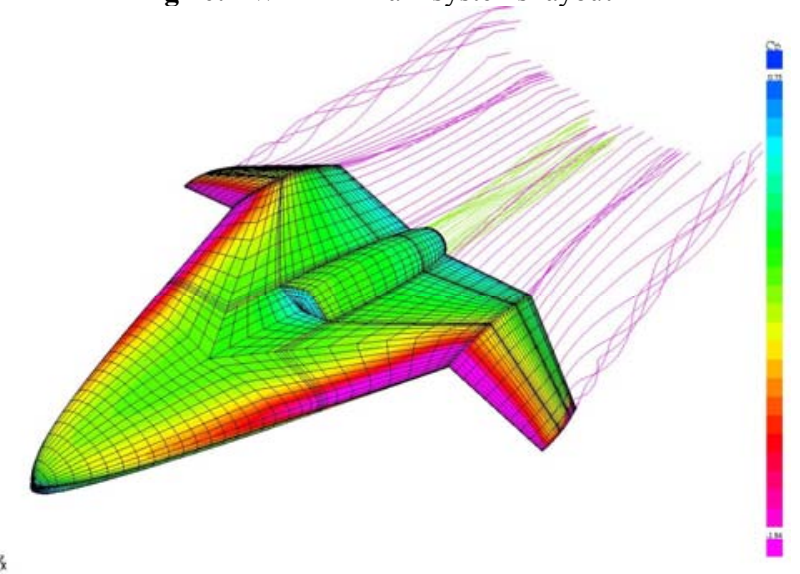

Fig 11. 1 PW-124 aircraft -6200 panels, 28 patches

NACA $65_{1}-012$ airfoils in the outer wings were selected, mainly due to their high $\mathrm{CL}\left(\mathrm{C}_{\mathrm{L}, \mathrm{MAX}}=1.65\right.$ at $\mathrm{Re}=28 * 10^{6}$ ) needed at transfer flight regime with $\mathrm{Ma}=0.5$ and for manoeuvring. For the outer wing, a medium swept angle equal to $30^{\circ}$ at $25 \%$ chord line was chosen. The 
central (wing-body) part has corresponding swept angle equal to $65^{\circ}$. Dihedral angles are equal to $-31^{\circ}$ for the outer wing and $+19.6^{\circ}$ for the central (wing-body) part. Wing geometry will however, be changed in the future to decrease radar signature [34]. The edges, all access panels, and major breaks in the surfaces will be grouped on a minimum number of alignments, see Figs. 12, 13. This will help to ensure that radar will see the strongest edge reflections only at a limited number of relatively narrow azimuth zones. This will give the illuminating radar one good return when the alignment is ideal, but much weaker return on subsequent sweeps.

A special effort will be devoted to designing a "single$\mathrm{S}$ " engine intake to protect the aircraft against strong radar signature coming from rotating engine blades, Figs. 10 and 14 [34].

\section{Aerodynamic characteristic of aircraft}

The aircraft surface was divided into a number of small panels, and each panel was assumed to have constant pressure distribution. The average number of panels (depending on configuration and specific version) was about 7,000 .

The resulting pressure distributions (selected examples) are shown in Figs. 15-18. Fig. 15 presents pressure distribution over the aircraft surface corresponding to angle of attack equal to $10^{\circ}$ at symmetrical flow with all the control surface undeflected. Fig. 16 shows pressure distribution also for all the control surface undeflected, at an angle of attack equal to $3.38^{\circ}$ (corresponding to steady horizontal flight at speed of $170 \mathrm{~m} / \mathrm{s}$ ) and an angle of sideslip equal to $10^{\circ}$. Fig. 17 presents symmetrical pressure distribution at $\alpha=3.38^{\circ}, \beta=0^{\circ}$, and both flap-tabs deflected on $10^{\circ}$. Fig. 18 presents asymmetrical pressure distribution with elevons deflected antisymmetrically, i.e. $\alpha=3,38^{\circ}$, $\beta=0^{\circ}, \delta_{\mathrm{F}}=0^{\circ}, \delta_{\mathrm{E}, \mathrm{l}}=+10^{\circ}, \delta_{\mathrm{E}, \mathrm{r}}=-10^{\circ}$.

Drag coefficient consists of parasite components (Tab. 5) depending on wetted area and the induced drag depending on lift coefficient. Breakdown of drag coefficient is presented in Tab. 5 .

Table 5. $\mathrm{C}_{\mathrm{D} 0}$ breakdown

\begin{tabular}{|l|c|c|c|}
\hline Parasite drag & $\mathbf{C}_{\mathbf{D}}$ & $\mathbf{S}_{\mathbf{i}}$ (reference area) & $\mathbf{C}_{\mathbf{D i}}{ }^{*} \mathbf{S}_{\mathbf{i}} / \mathbf{S}$ \\
\hline Outer wing & 0.009 & 2.16 & 0.0016 \\
\hline Central part (fuselage) & 0.020 & $9 ., 72$ & 0.0164 \\
\hline Total parasite drag & & $\mathbf{1 1 . 8 8}$ & $\mathbf{0 . 0 1 7 9 6}$ \\
\hline
\end{tabular}

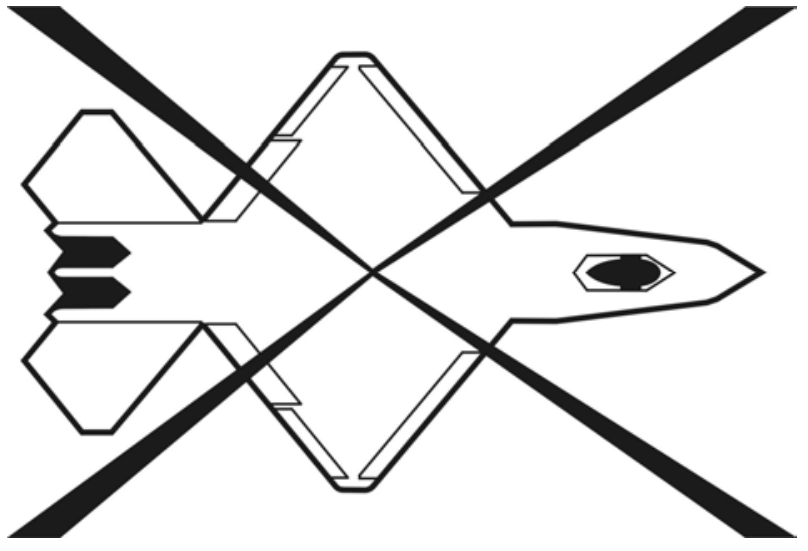

Fig 12. The edges, panels, and major brakes in the surfaces have to be grouped on a minimum number of alignments. These helps to ensure that radar will see the strongest edge reflections only at four relatively narrow azimuth zones. This will give the illuminating radar one good return when alignment is ideal, but a much weaker return on subsequent sweeps. After R. Whitford [34]

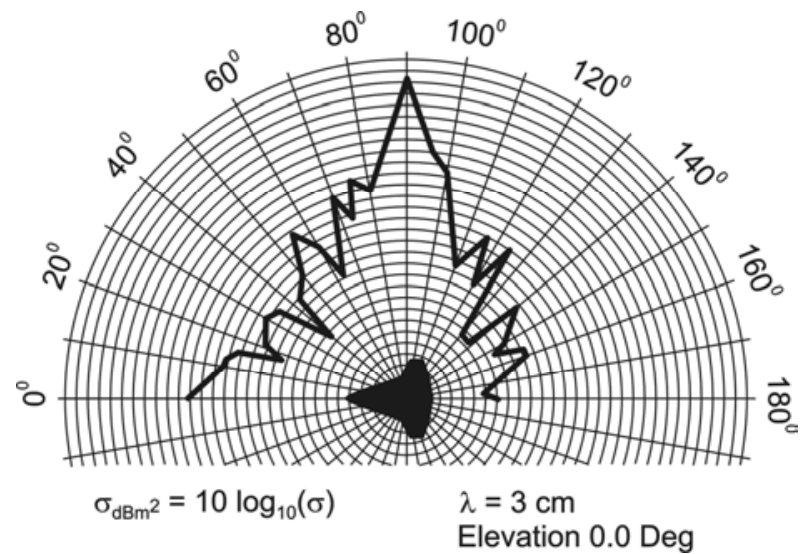

Fig 13. Predicted signature of a generic aircraft illuminated by 3 $\mathrm{cm}$ wavelength radar. Includes surface reflections and edge diffraction but excludes corners, tips, and double reflections. From the front up to the azimuth $30^{\circ}$, the box type air intakes totally dominate the signature. More than $60 \%$ of RCS at $65^{\circ}$ is due to the wing leading edge. After R. Whitford [34]

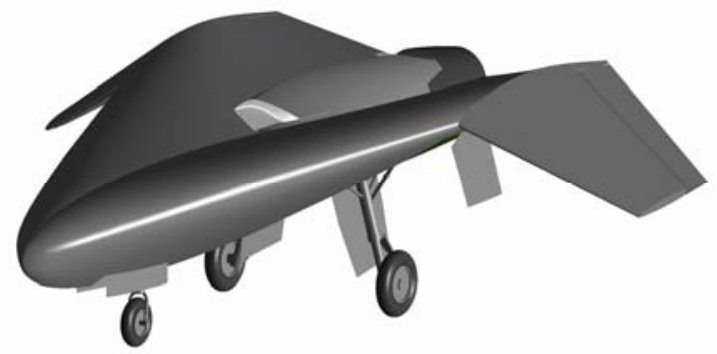

Fig 14. PW-124 aircraft - engine inlet is visible the body top surface 


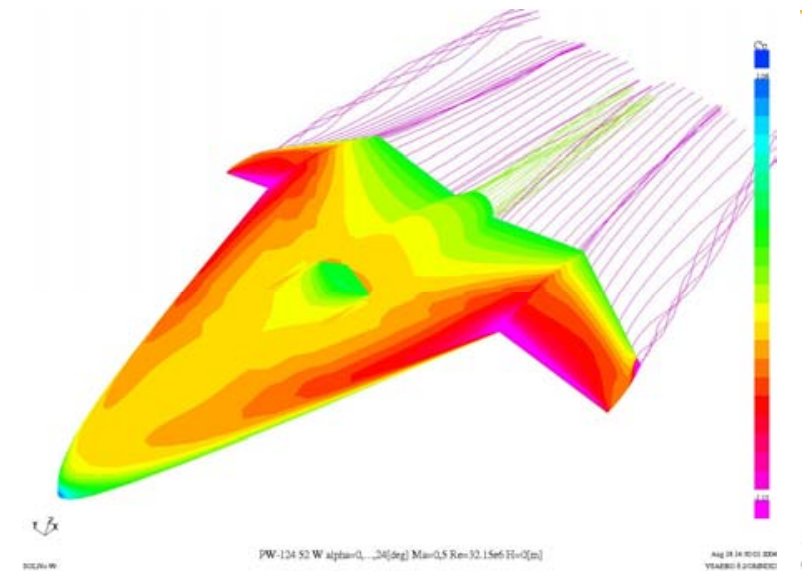

Fig 15. Cp distribution for PW-124 aircraft at $\alpha=10^{\circ}$

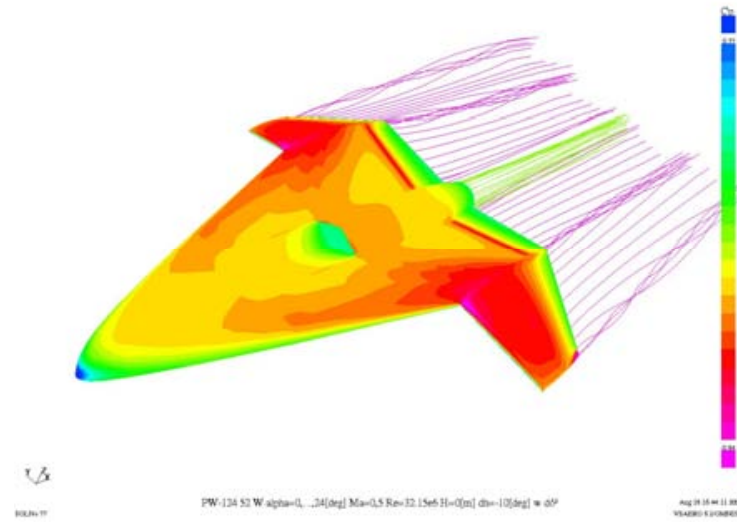

Fig 17. Cp distribution for PW $-124 \mathrm{HALE}$ aircraft at $\alpha=3.38^{\circ}, \beta=0^{\circ}, \delta_{\mathrm{F}}=10^{\circ}$

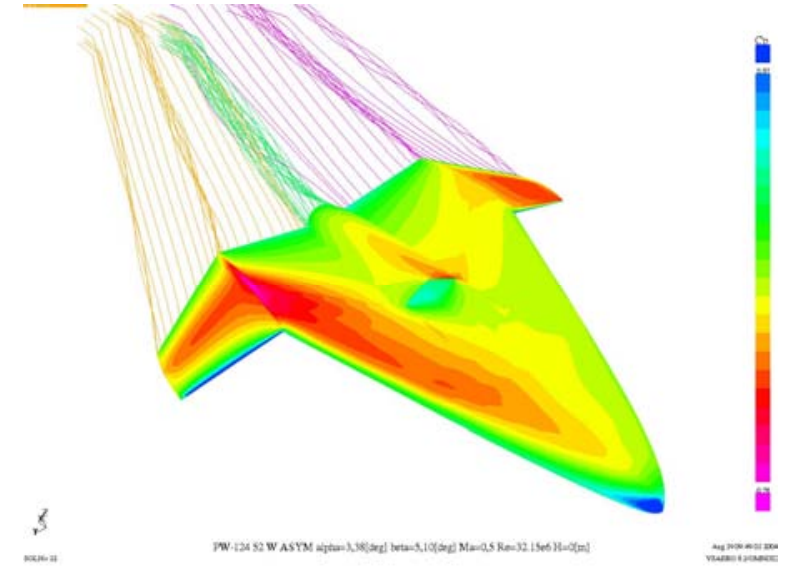

Fig 16. Cp distribution for PW-124HALE aircraft at $\alpha=3.38^{\circ}$, $\beta=10^{\circ}$

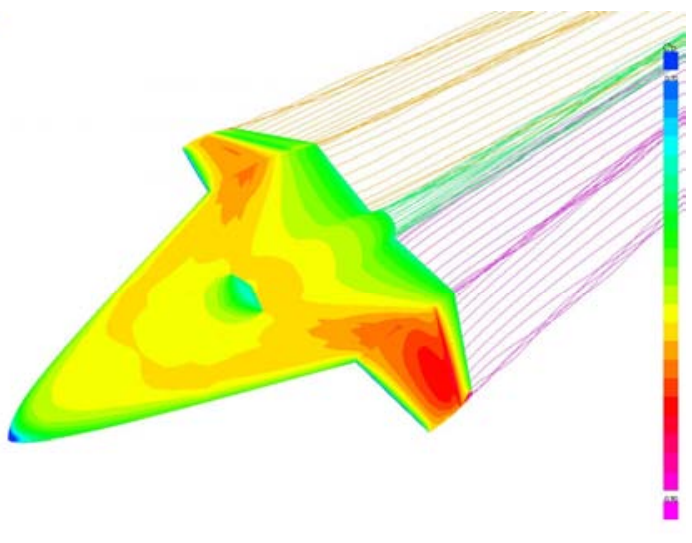

Fig 18. Cp distribution for PW -124 HALE aircraft at $\alpha=3.38^{\circ}, \beta=0^{\circ}, \delta_{\mathrm{F}}=0^{\circ}, \delta_{\mathrm{E}, \mathrm{l}}=+10^{\circ}, \delta_{\mathrm{E}, \mathrm{r}}=-10^{\circ}$

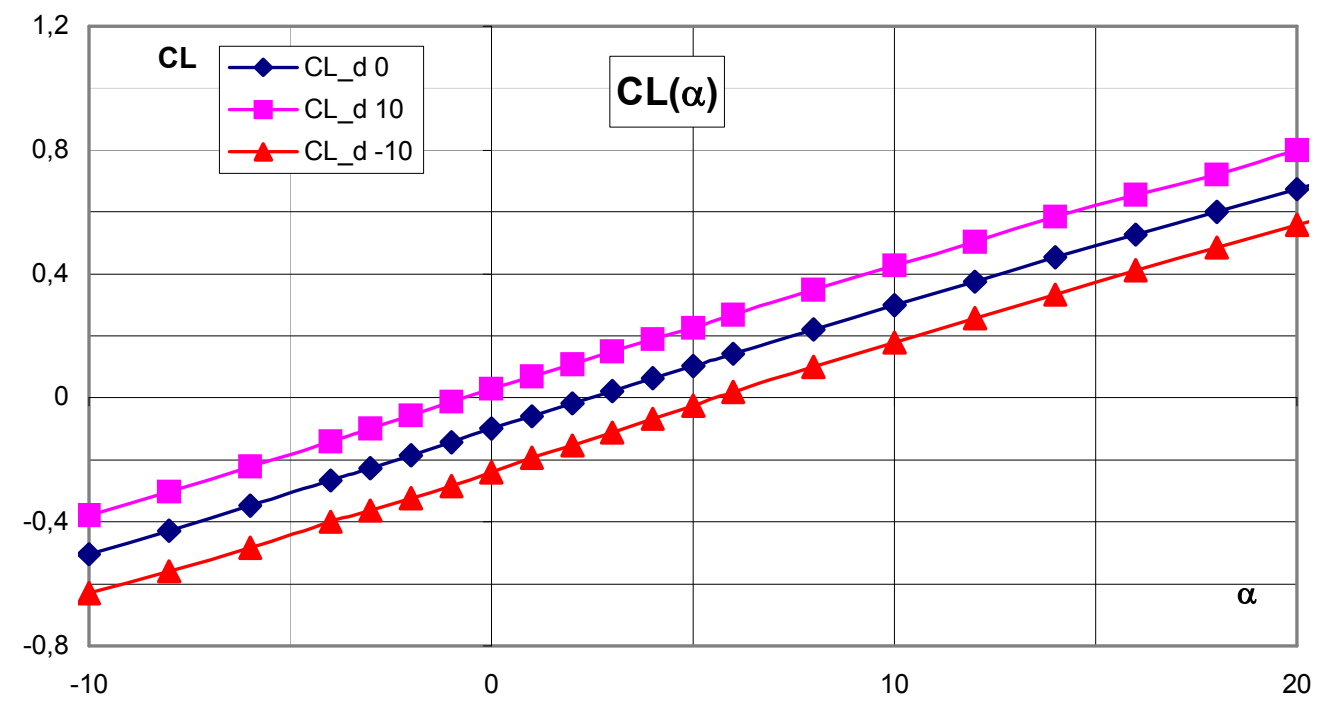

Fig 19. Lift coefficient versus angle of attack for clean conFig. uration $(\mathrm{d}=0)$, flap-tabs deflected down $(\mathrm{d}=10)$, and flap-tabs deflected up $(\mathrm{d}=-10) ; \mathrm{Ma}=0.5, \mathrm{Re}=28 \times 10^{6}$ 


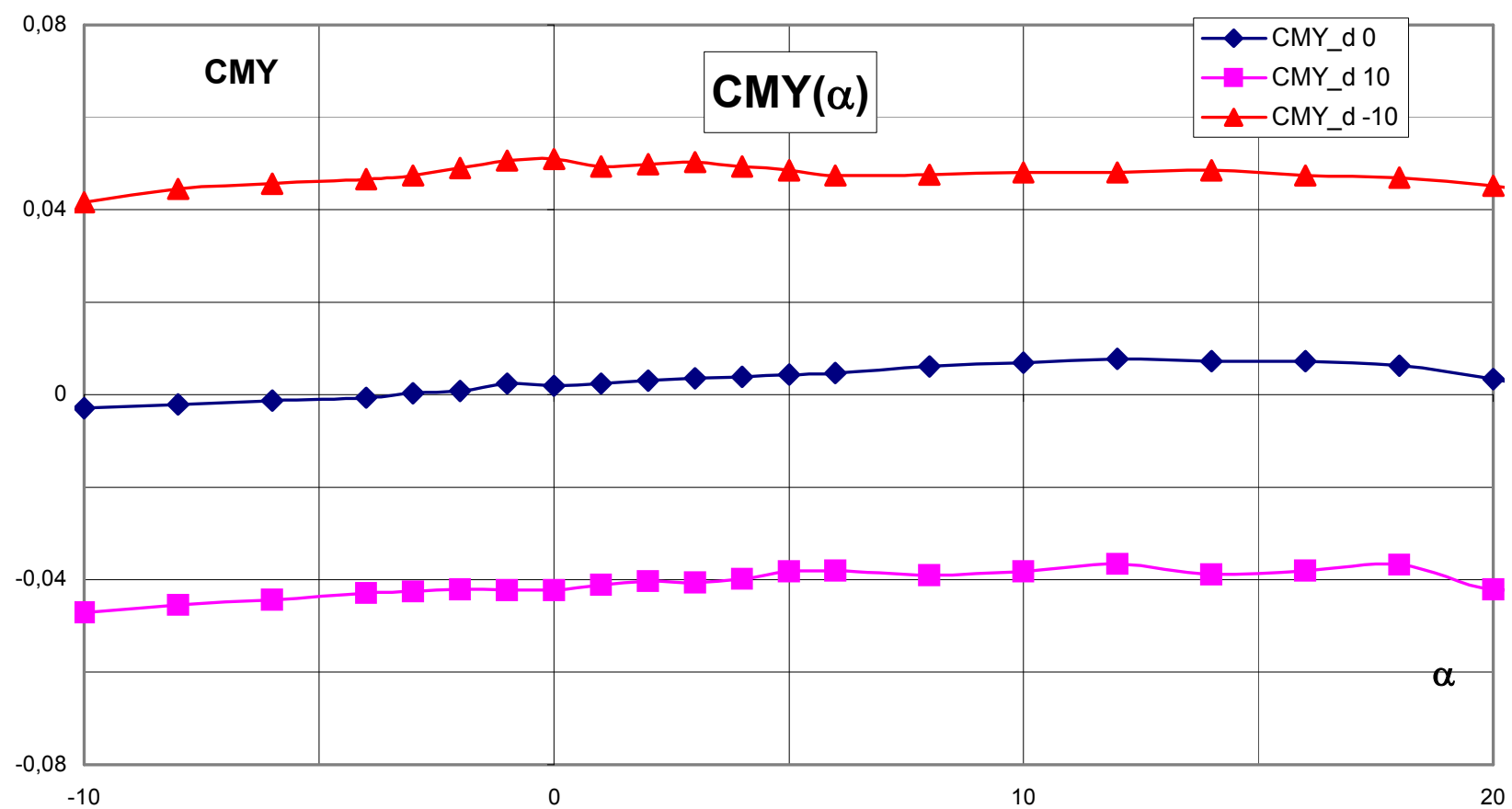

Fig 20. Pitching moment coefficient computed about a quarter point of $M A C$ versus angle of attack for clean configuration (d=0), flaptabs deflected down $(\mathrm{d}=10)$, and flap-tabs deflected up $(\mathrm{d}=-10) ; \mathrm{Ma}=0.5, \mathrm{Re}=28 \times 10^{6}$

The influence of the boundary layer on lift and pitching moment was also investigated. It was found that in most of cases at small flight altitudes and at small angles of attack the influence of boundary layer on lift and pitching moment can be neglected. It is however not the case at high angles of attack, and that is the reason why in all computational procedures when the aerodynamic characteristics were approximated, the boundary layer was included into the computational model.

Conditions of longitudinal equilibrium (trimming) were found for a number of altitudes, weights, and flight scenarios. Also, a classical static and dynamic stability analysis were performed, and some results led to changes in the layout of the aircraft.

\section{E. Sensitivity to gusts}

One important feature of any UAV is its sensitivity to gusts [11]. The lower the sensitivity, the better the design. Low sensitivity to gusts can be achieved by either a low lift-curve slope $\mathrm{C}_{\mathrm{L} \alpha}$ (low $\mathrm{C}_{\mathrm{L} \alpha} \rightarrow$ low $\mathrm{W} / \mathrm{W}_{\mathrm{g}} \rightarrow$ low acceleration $\rightarrow$ low $\mathrm{n} \rightarrow$ low sensitivity) or by high wing loading (high mg/S $\rightarrow$ low S/mg $\rightarrow$ low W/W $\rightarrow$ low acceleration $\rightarrow$ low $\mathrm{n} \rightarrow$ low sensitivity). It follows directly from the mathematical model expressed by equations (1-4).

$\Delta \alpha=\frac{W_{g}-W}{V}$

$$
\begin{aligned}
& m \dot{W}=\frac{1}{2} \rho V^{2} S \frac{W_{g}-W}{V} C_{L \alpha}, \\
& m \dot{W}+q S \frac{C_{L \alpha}}{V} W=q S \frac{C_{L \alpha}}{V} W_{g}, \\
& \frac{W}{W_{g}}=\left(1-e^{-\frac{q S C_{L \alpha}}{m V} t}\right)
\end{aligned}
$$

where: $\mathrm{W}_{\mathrm{g}}$ - vertical gust (positive if upwards); $\mathrm{W}$ aircraft vertical speed (positive if upwards); V - aircraft horizontal speed; $\Delta \alpha$ - increase of the angle of attack; $\mathrm{m}$ aircraft weight; $\mathrm{S}$ - wing area; $\mathrm{C}_{\mathrm{L} \alpha}$ - lift-curve slope; $\rho$ - air density; $\mathrm{q}$-dynamic pressure; $\mathrm{t}$ - time.

Fig. 21 compares the vertical speed of aircraft disturbance after a vertical gust. From this figure, it also follows that UAVs are less sensitive to gusts at a lower liftcurve slope (under the assumptions that two different UAVs with different lift-curve slopes fly with the same speed and that the gusts are exactly the same). The UAV with a lower lift-curve slope has the lower normal load coefficient. It has to be emphasised that in order to design UAV with lower sensitivity the designer has to decrease the lift-curve slope. However many other performance parameters also depend on lift-curve slope, and a trade-off is required between gust sensitivity, take-off and landing distance, and induced drag at high speeds. 


\section{F. Wing design}

Wing design was based on the load envelope presented in Fig. 22, which was designed following JAR-23 requirements. Selected performances are shown in Fig. 23, on the so-called flight envelope. Range and endurance are computed and shown in Fig. 24.

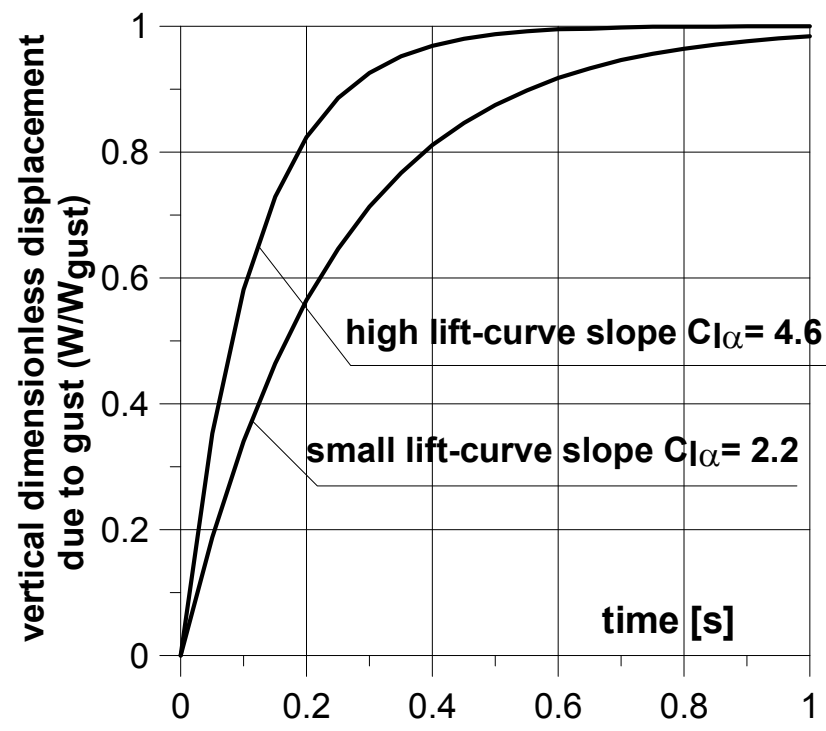

Fig 21. A simple physical model explaining why an aircraft with a lower aspect ratio (and therefore with a in lower lift-curve slope) is less sensitive to gusts than one with a higher aspect ratio
Aircraft structure can be divided into two main parts: the blended wing-body (central part) and the outer wing. The outer wing consists of: torsion box, nose with fixed slot, and movable elevon (or rudderon). The double-circuit torsion box made of epoxy-carbon composite takes the torsion loading. Upper and lower skins are made of sandwich with the filler made of polyurethane foam. The Torsion box contains front and rear spar. Spar flanges are made of carbon roving. Their sections were designed to use all fibres in the most efficient way. Spars walls are made of sandwich using carbon fabric and polyurethane foam. Control surfaces skins (both noses and rear skins) and internal walls are also designed as sandwich and are made of carbon fabrics.

Initial design assumes application of two layers of fabric with a specific weight of $163 \mathrm{~g} / \mathrm{m}^{2}$ (similar to Interglas 98131) and two layers of fabric with a specific weight of $93 \mathrm{~g} / \mathrm{m}^{2}$ (similar to Interglas 98110) for the structure of the skins. This gives a shear stress level of $20 \mathrm{MPa}$ in the most loaded region of the skin. The number of layers in the spar walls will be variable along the span. There will be about ten layers of fabric with a specific weight of $285 \mathrm{~g} / \mathrm{m}^{2}$ (similar to Interglas 98160) near the wing brackets. Wing loading causes stress level of about $80 \mathrm{MPa}$ in the D point of the manoeuvring envelope. Front and rear spar walls have structures made of three layers of fabric with a specific weight of $163 \mathrm{~g} / \mathrm{m}^{2}$. Shear modulus $\mathrm{G}=7 \mathrm{GPa}$ was assumed.

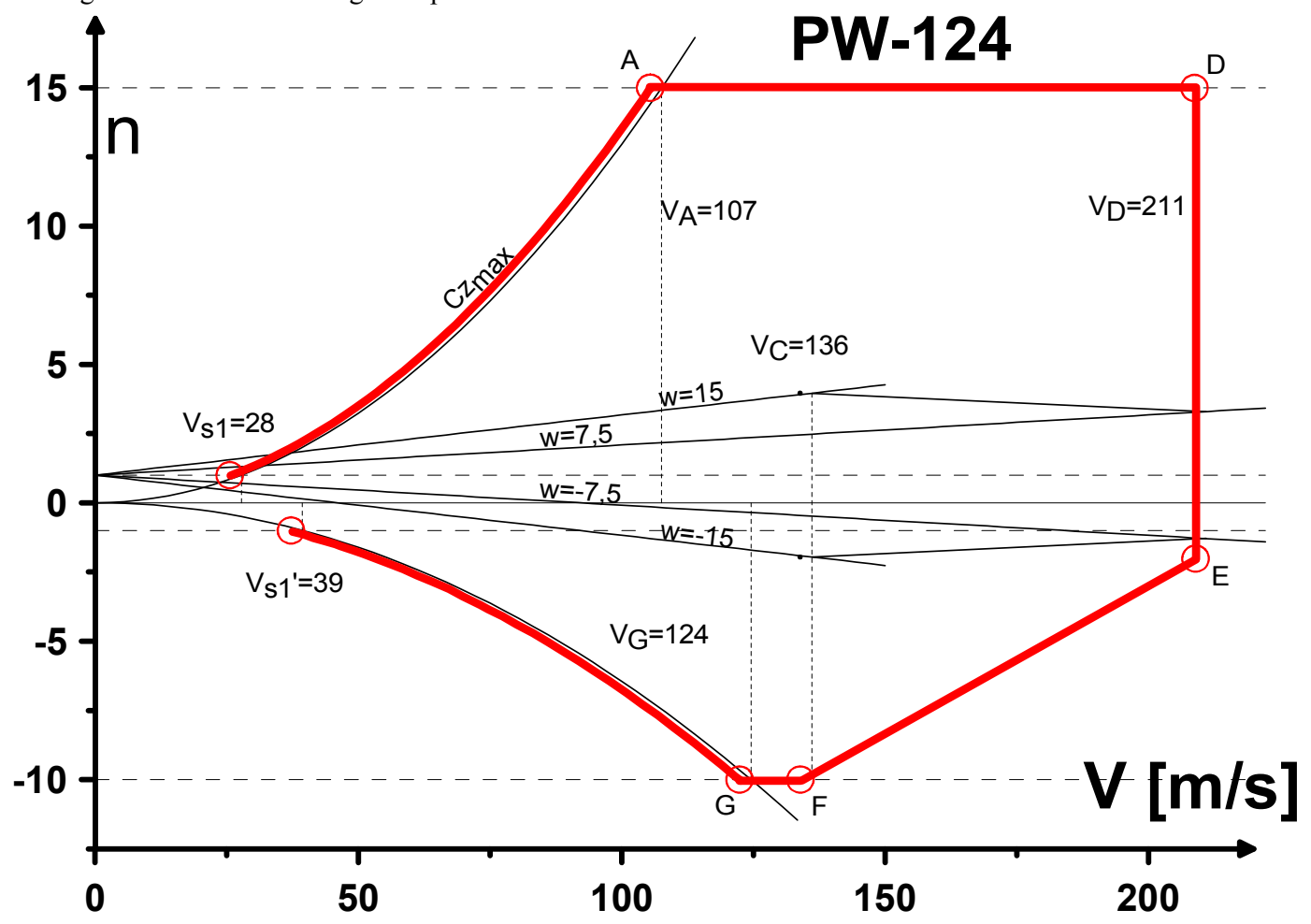

Fig 22. Load factor envelope 


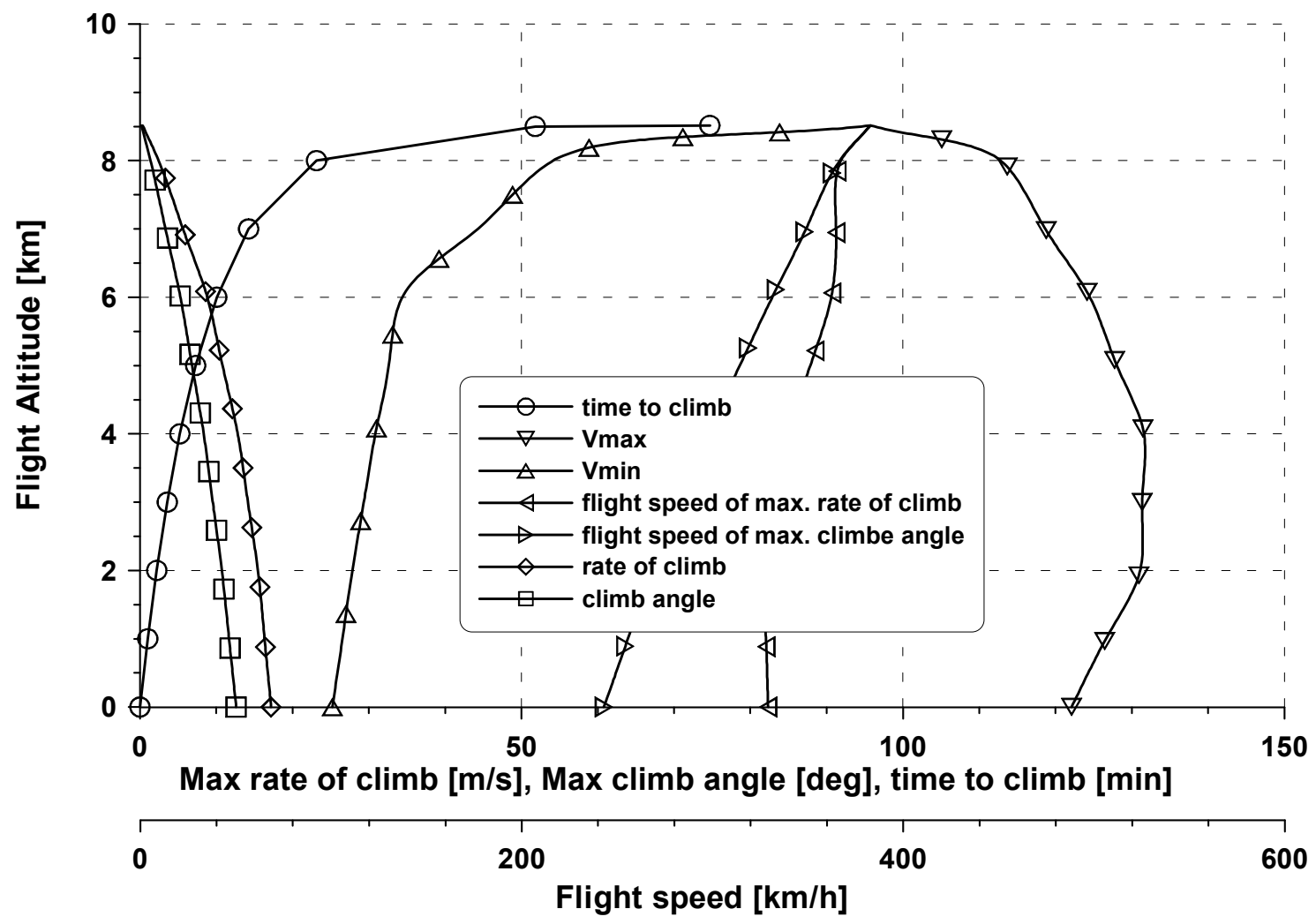

Fig 23. Flight envelope

PW-124 - Endurance and Range $\left(H=1.5 \mathrm{~km}, W=900 \mathrm{~kg}, \mathrm{~W}_{\mathrm{FUEL}}=350 \mathrm{~kg}\right)$

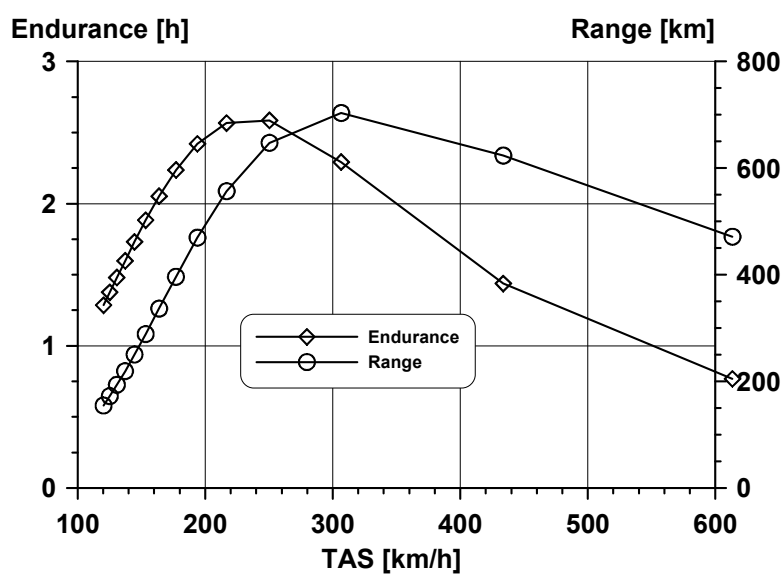

Fig 24. Endurance and range versus flight speed

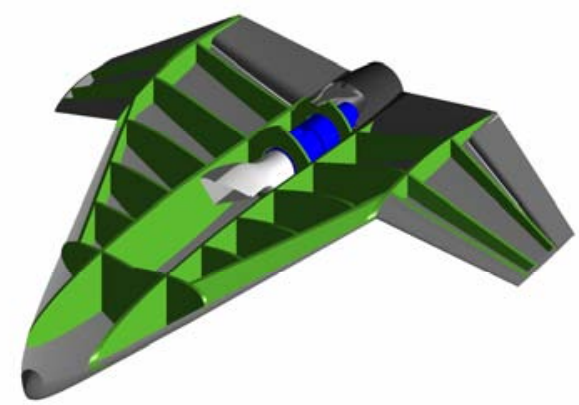

Fig 25. An approximated layout of aircraft structure

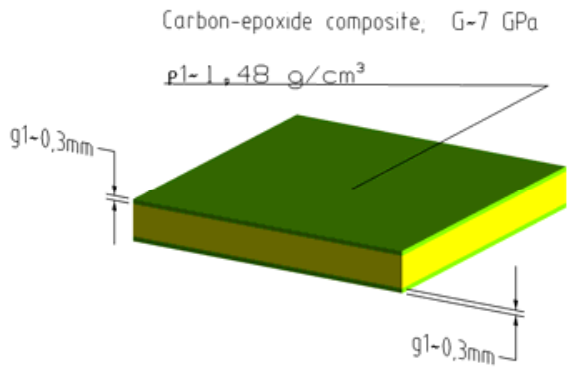

Fig 26. Sandwich skin used at outer wing design

Spars flanges are designed so that the stress level is constant along the wing span. The initial design of the control surfaces assumes the application of two layers of carbon fabric with a specific weight of $163 \mathrm{~g} / \mathrm{m}^{2}$ and one layer with fabric that has a specific weight of $93 \mathrm{~g} / \mathrm{m}^{2}$. There will be three layers of fabric with a specific weight of $163 \mathrm{~g} / \mathrm{m}^{2}$ in the walls.

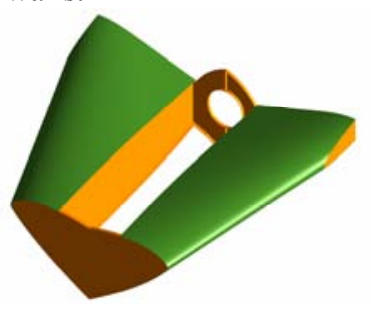

Fig 27. Payload compartment 


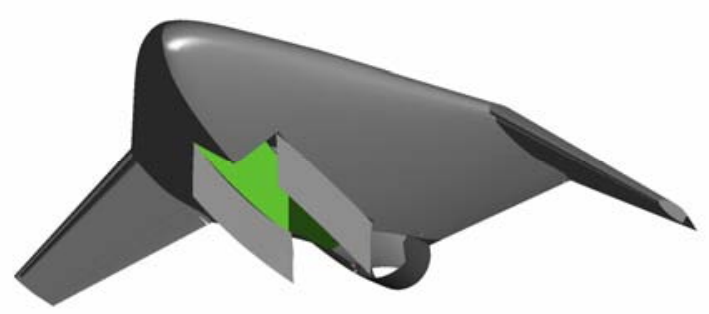

Fig 28. Payload containers opened in flight - both covers are deflected down

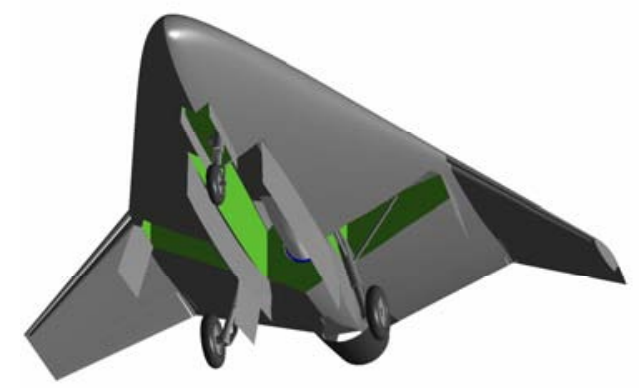

Fig 29. Internal payload containers are opened, all undercarriage legs deflected down. Double covers of each undercarriage containers are visible

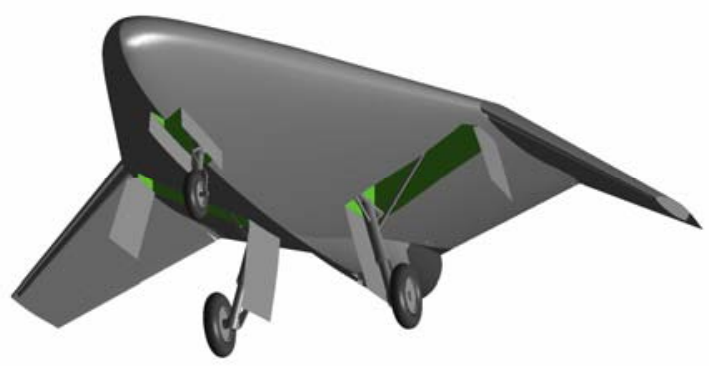

Fig 30. Internal payload containers are closed, all undercarriage legs deflected down. Double covers of each undercarriage containers are visible. Aircraft is ready to land. This is a bottomside view

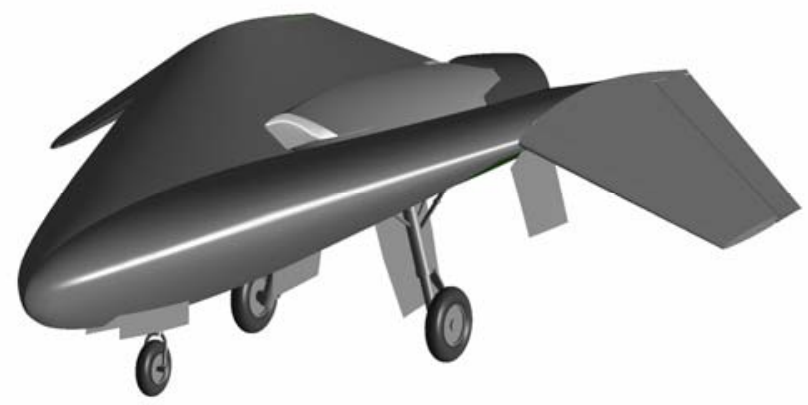

Fig 31. Internal payload containers are closed, all undercarriage legs deflected down. Double covers of each undercarriage containers are well visible. Aircraft is ready to land (This figure supplements Fig. 29 and is a top-side view)

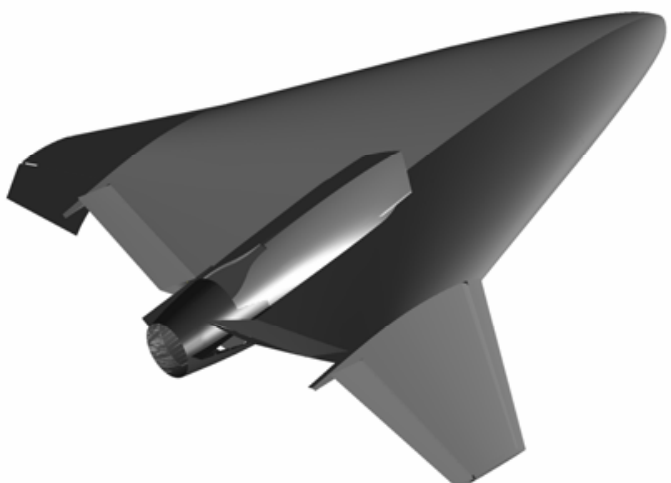

Fig 32. Flap-tabs (at the trailing edge of the blended-wing body) deflected up (it is typical in horizontal flight for equilibrium of pitching moments). Elevons deflected asymmetrically (left elevon deflected down, right deflected up)

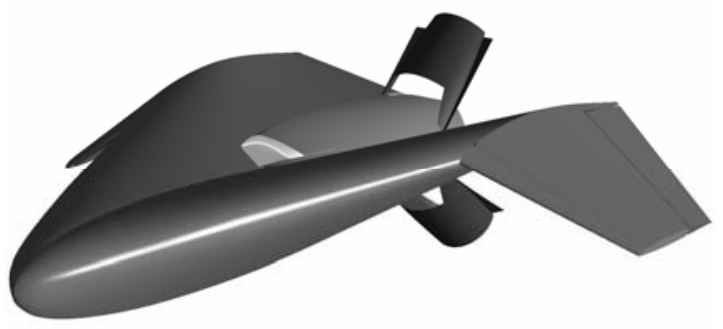

Fig 33. Clean configuration from a top-front-side view. Flight spoilers deflected

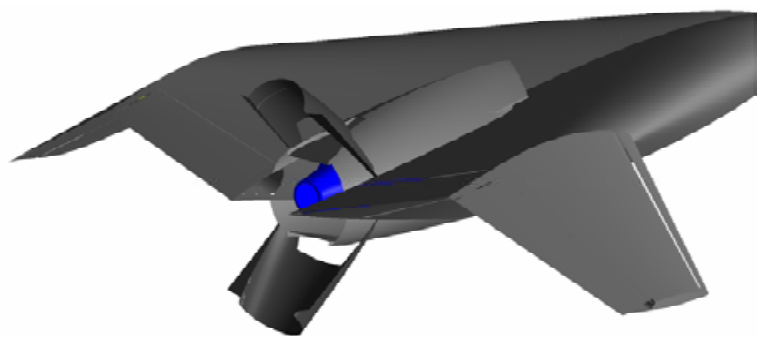

Fig 39. Clean configuration from a top-back-side view. Flight spoilers deflected. Exhaust nozzle (blue) is visible

\section{Conclusion and recommendation}

As usual in most design projects, a trade-off between aerodynamic efficiency, manoeuvrability, sensitivity to gusts, reduced radar signature, performance, flight stability, selection of the flight control system, payload and sensor volume, reliability, and safety has to be performed. The set of requirements, in order of importance, for the PW-124 aircraft include high manoeuvrability, low sensitivity to gusts, and reduced radar, infrared, and noise signature. Combat agility (understood as manoeuvrability in the neighbourhood of stall angle of attack) can be assessed by a number of parameters, including the so-called "pointing margin" $(\mathrm{PM})$, relative energy state $\left(\mathrm{V} / \mathrm{V}_{\mathrm{C}}\right)$, combat cycle time (CCT) for characterising pitch agility, and the 
rearward separation distance (RSD) for characterising roll agility. Further studies are needed to understand the mutual relations between all these agility parameters. In this paper, pointing margin (PM), combat cycle time (CCT), and sensitivity to gust were taken into account for selecting the wing loading. Design details presented in this paper supplements the general concept and are shown to understand how the trim conditions, stability, and control can be achieved to fulfil the flight mission.

\section{References}

1. Allouche M. Civil UAV Safety Issues Airworthiness \& Operational Certification aspects. UAVNET, Stockholm, 2001 Oct. // Website: www.uavnet.com

2. CAPECON Project No GRD1-2001-40162. Civil UAV Applications \& Economic Effectivity of Potential Cionfiguration Solutions // Technical documents. - V FR of European Union, 20022004.

3. Fransaer D., Lissens G. PEGASUS, the future of remote sensing. UAVNET meeting in Eilat, 2002 Oct. // Website: www.uavnet.com

4. Frydrychewicz A., Goraj Z., Wortman A. Small Unmanned Aerial Vehicles - Reconnaissance and Observation Target Designation Traking and Pursuit Intercept". Design Conceptual Project submitted for DARPA. - Santa Monica, 1996 Dec. (unpublished).

5. Frydrychewicz A., Goraj Z., Wortman A. Unmanned Delivery Vehicle Phantom - Single and Distributed Payloads Low Observables". Design Conceptual Project submitted for DARPA. - Santa Monica, 1997 Jan. (unpublished).

6. Fulghum D., Wall R. Israel Pursues High Tech Despite War Costs // Aviation Week \& Space Technology. - 2002, June 24. - P. 78-80.

7. Fulghum D, Wall R. Israel's Future Includes Armed, Long-Range UAVs // Ibid. - P.83-84.

8. Goodman G. Jr. Manned-Unmanned Synergy US Army UAV-Related Efforts Gain Momentum // Armed Forces Journal International. - 2002, July. - P. 56-61.

9. Goraj Z. Civilian Unmanned Aerial Vehicles Overview of European Effort and Challenges for the Future // Aviation. - Vilnius: Technika, 2003. - Vol VII, No 2. - P. 1- 18.

10. Goraj Z. Design and Flight Dynamics of a HALE UAV - HARVE-2. Workshop for the Advancement of Unmanned Air Vehicles. - Paper 9. $-15 \mathrm{p}$.

11. Goraj Z. Dynamic characteristics of different UAV conFig. urations. UAVNET Capua meeting, 2002 Feb. // Website: www.uavnet.com
12. Goraj Z. Dynamics of a High Altitude Long Endurance UAV. ICAS Congress. - Harrogate, 2000. - Paper 362.

13. Goraj Z. PW-125 MALE UAV design project developed in Warsaw University of Technology. AIAA $3^{\text {rd }}$ conference "Unmanned Unlimitted", Chicago, 2004, Sept. // AIAA paper 6326.

14. Goraj Z., Frydrychewicz A. Design challenges associated to development of a new generation UAV // Proceedings of the First International Conference on Unmanned Arial Vehicles. Kielce: Kielce University of Technology, 2004, May 19. - P. 161-168 (in Polish).

15. Goraj Z., Frydrychewicz A., de'Tallec C. et al. HALE UAV platform optimised for a specialized $20-\mathrm{km}$ altitude patrol mission // Proc. of $24^{\text {th }}$ ICAS Congress. - Yokohama, 2004. - Paper 285.

16. Goraj Z., Frydrychewicz A. Development Approach of the PW_103 - An Increased Reliability MALE UAV - Under the CAPECON Project within the V FR of EU // Ibid. - Paper 443.

17. Goraj Z., Frydrychewicz A., Gadomski J. Polish UCAV Programme - an Initiative and Effort Undertaken at Warsaw University of Technology. UCAV Conference, London 2004 // Website: ftp://miguel:upld05@ftp.iqpc-files.co.uk/2249

18. Goraj Z. Frydrychewicz A., Świtkiewicz R. et al. High Altitude Long Endurance Unmanned Aerial Vehicle of a New Generation - a Design Challenge for a Low Cost, Reliable And High Performance Aircraft // Bulletin of Polish Academy of Sciences. - 2004. - Vol 52, No 3. - P. 173-194.

19. Goraj Z. Frydrychewicz A., Winiecki J. Design Concept of a High Altitude Long Endurance Unmanned Aerial Vehicle. Aircraft Design // An International Journal. - 1999. - Vol 2. - P.19-44.

20. Goraj Z. Ransom Ph., Wagstaff P. Dynamics and design aspects of future UAV's // Aviation. Vilnius: Technika, 2003. - Vol VII, No 3. - P. 2036.

21. Goraj Z. Ransom Ph., Wagstaff P. From Specification \& Design Layout to Control Law Development for Unmanned Aerial Vehicles Lessons Learned from Past Experience // Proceedings of V European Workshop on Aircraft Design Education, Linköping, Sweden, June 2-4, 2002. - Linköping, 2002. - P. 17-21.

22. Goraj Z. Suchodolski S. Unmanned Aerial Vehicles of Increased Safety Level // Proc. of VI Conference on "Investigation Methods and Flight Tests of Aircraft", June 2004. - 2004. - P. 161168 (in Polish).

23. Goraj Z. Ueda T. Ultra Light Wing Structure for High Altitude Long Endurance UAV. ICAS Congress. 2000, Harrogate, England. - Harrogate, 2000. - Paper 476. 
24. Herbst W.B., Krogull B. Design for Air Combat // AIAA paper, AIAA-72-749. - Los Angeles, 1972. August 7-9.

25. Holder B. Unmanned Air Vehicles - An Illustrated Study of UAVs /Copyright @ 2001 by Bill Holder.

26. Jane's Unmanned Aerial Vehicles and Targets / Edited by K. Munson. - Couldson: Surrey CR5 2YH, UK, 2001. - Ed.17.

27. Morag A. Aurora Flight Sciences Corporate Overview". Eilat UAVNET meeting, Oct. 2002 // Website: www.uavnet.com

28. Morag A. UNITE UAV National Industry Team. - Ibid.

29. Tamrat B.F. Fig. hter Aircraft Agility Assessment Concept and Their Implication on Future Agile Fig. hter Design // AIAA paper. - Washington D.C., 1988.

30. Tsach Sh. Advanced Technologies for Civil Applications UAV's. Rochester UAVNET meeting, July 2002 // Website: www.uavnet.com
31. Tsach Sh., Yaniv A., Avni H. et al. High Altitude Long Endurance (HALE) UAV for Intelligence Missions $/ / 20^{\text {th }}$ ICAS Proceedings. - 1996, Sept. Vol I. - P. 368-379.

32. Vitali J., Tsach S., Avni H. Development Approach of the HERON Medium Altitude Long Endurance UAV // Ibid. - P. 380-390.

33. Website: www.uavnet.com

34. Whitford R. Stealth from the Aircraft Designer's Viewpoint // Proceedings of 3-rd International Seminar on "Recent Research and Design Progress in Aeronautical Engineering and its Influence on Education. IAAM Research Bulletin. - Warsaw, 1998. - No 8. - P. 35-45.

35. Wortman A., Wyszkowski C., Frydrychiewicz A. et al. High Altitude Reconnaissance Vehicle Enterprise. Design Conceptual Project submitted for DARPA. - Santa Monica, 1995 (unpublished).

36. Yaniv A. Review of IAI Advanced Design HALE UAV Activities. UAVNET Eilat meeting, Oct. 2002 // Website: www.uavnet.com 